\title{
Control the deposition uniformity using ring cathode by DC
}

\section{discharge technique}

\author{
Kadhim A. Aadim, Muhammad O. Salman \\ Department of Physics, College of Science, University of Baghdad, Iraq \\ E-mail:kadhim_adem@scbaghdad.edu.iq
}

\begin{abstract}
Simulation of direct current (DC) discharge plasma using COMSOL Multiphysics software were used to study the uniformity of deposition on anode from DC discharge sputtering using ring and disc cathodes, then applied it experimentally to make comparison between film thickness distribution with simulation results. Both simulation and experimental results shows that the deposition using copper ring cathode is more uniformity than disc cathode.
\end{abstract}

Key words

Simulation, $D C$

discharge, sputtering.

Article info.

Received: Aug. 2016

Accepted: Oct. 2016

Published: Mar. 2017

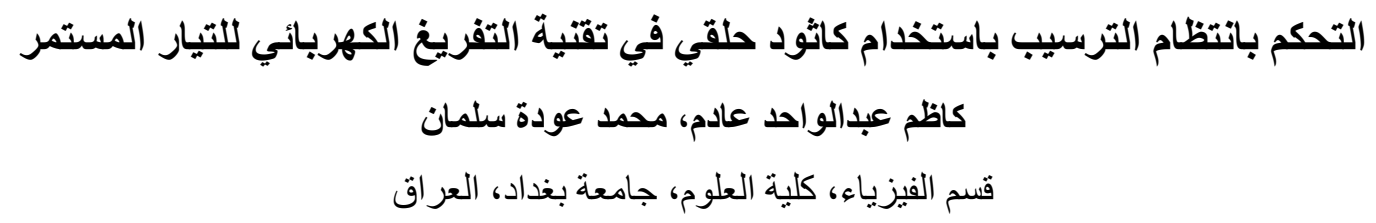

الخلاصة

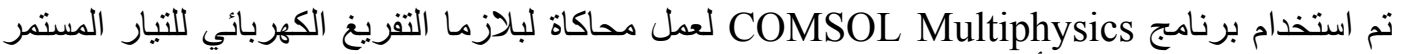

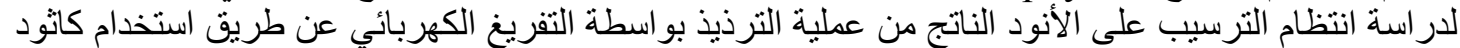

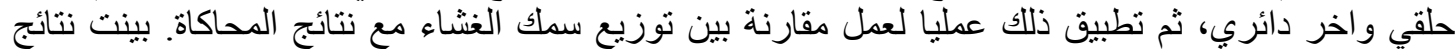
المحاكاة والنتائج العملية أن الترسيب باستخدام كاثود حلقي من النحاس أكثر انتظاما من الكانود الدائري.

\section{Introduction}

In the last decade, many researches deal with DC glow discharge modelling to investigate the suitable arrangement for specific application[1$3]$.

For many plasma applications, fluid moment (density, flow velocity, temperature) descriptions of a charged particle species in a plasma are sufficient. Continuity equation for all species and energy within the plasma, Maxwell's equations and Boltzmann equations were solved as a system [4].

COMSOL Multiphysics package based on finite element method. The differential equations describing the motion of species numerically for a finite number of spatial points taking into account their interaction with the applied electric field into consideration.

\section{Mathematical model}

Plasma simulating by finite element modeling (FEM) is used to make approximate solution for differential equations which describe the drift diffusion approximation [5]. Which contents electron and electron energy conservation equations, the heavy species diffusion transport equation and the Poisson's equation into the suitable form describe dc discharge problems, then solved the difference equations numerically. 
The electron density $\left(n_{e}\right)$ and mean electron energy $\left(n_{\varepsilon}\right)$ are computed by solving a pair of drift-diffusion equations for the electron density and mean electron energy [6].

$\frac{\partial n_{e}}{\partial t}+\nabla \cdot \Gamma_{e}=S_{e}$

$\frac{\partial \mathrm{n}_{\varepsilon}}{\partial t}+\nabla \cdot\left[-n_{\varepsilon}\left(\mu_{\varepsilon} . E\right)-D_{\varepsilon} . \nabla \varepsilon\right]+$

$E . \Gamma_{e}=S_{\varepsilon}$

while for ion is

$\frac{\partial n_{i}}{\partial t}+\nabla \cdot \Gamma_{i}=S_{i}$

where $S_{e}, S_{i}$ and $S_{\varepsilon}$ are the creation rate for electrons, ions and electron energy from energy difference in reactions, $\Gamma_{\mathrm{e}}$ and $\Gamma_{\mathrm{i}}$ denote the electron and ion flux and described by the following equations[3]

$\Gamma_{e}=-n_{e} \mu_{e} E-D_{e} \nabla n_{e}$

$\Gamma_{i}=n_{i} \mu_{i} E-D_{i} \nabla n_{i}$

while the flux of neutral species

$\Gamma_{n}=-D_{n} \nabla n_{n}$

where $\mu$ and $\mathrm{D}$ denoting the mobility and diffusion coefficients[7]

$$
\mu_{e, i}=\frac{e}{m_{e, i} v_{e, i}}, \quad D_{e, i}=\frac{K T_{e, i}}{m_{e, i} v_{e, i}}
$$

where $v$ is the collision frequency of electron with neutral particles. It is depends on the number density of target particles $\mathrm{N}$, mean relative velocity $(\bar{v})$ and the probability for this type of collision (collision crosssection $\sigma$ ) [8]

$v=\sigma \bar{v} \mathrm{~N}$

Mean relative velocity $(\bar{v})$ can be derived from the Maxwell-Boltzmann distribution [9]

$\overline{\mathrm{v}}=\left(\frac{8 \mathrm{k}_{\beta} \mathrm{T}}{\pi \mathrm{m}_{e}}\right)^{1 / 2}$

where $\mathrm{k}_{\beta}$ and $\mathrm{m}_{e}$ is the are Boltzmann constant and electron mas respectively.

$\mu_{\varepsilon}=\left(\frac{5}{3}\right) \mu_{e}, D_{\varepsilon}=\mu_{\varepsilon} T_{e}$

And using Poisson's equation for the electrostatic field [10]

$\epsilon_{0} \nabla . E=\sum_{k} q_{k} n_{k}$

where $\mathrm{E}$ is the electric field, $\mathrm{q}$ is the charge, $E=-\nabla \emptyset$

Free electrons will be accelerated and along its way, they collide with the gas atoms. These collisions can be classified into three types, elastic collision, excitation reaction, ionization reaction and step-wise ionization from metastable, as in Fig.1.

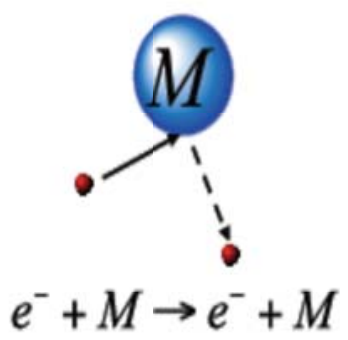

(a)

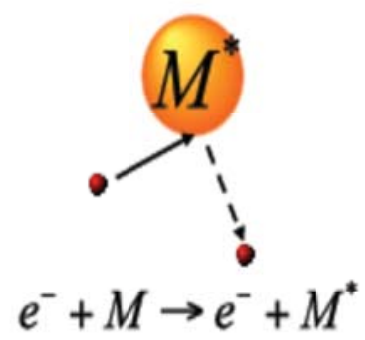

(b)

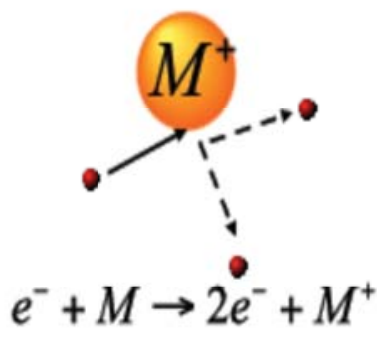

(c)

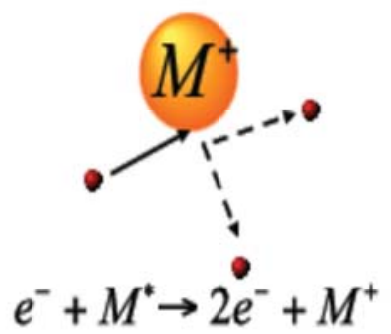

(d)

Fig. 1: Reactions between a free electron and neutral molecule (a) elastic collision (b)excitation reaction and (c) ionization reaction (d) step-wise ionization from metastable [11]. 
The collision frequency of electron with particles depends on the probability for this type of collision (collision cross-section). The cross section for three type of collisions (elastic, excitation and ionization collisions) are a function of electron energy [11]. High energy electrons have small chance to interact with outer shell electron because it past quickly. Also, at very low energy, because the electrons turn around an atom without interaction. The interactions occur over a narrow range of energy. Fig. 2 illustrates elastic and inelastic cross sections for argon atom [12].

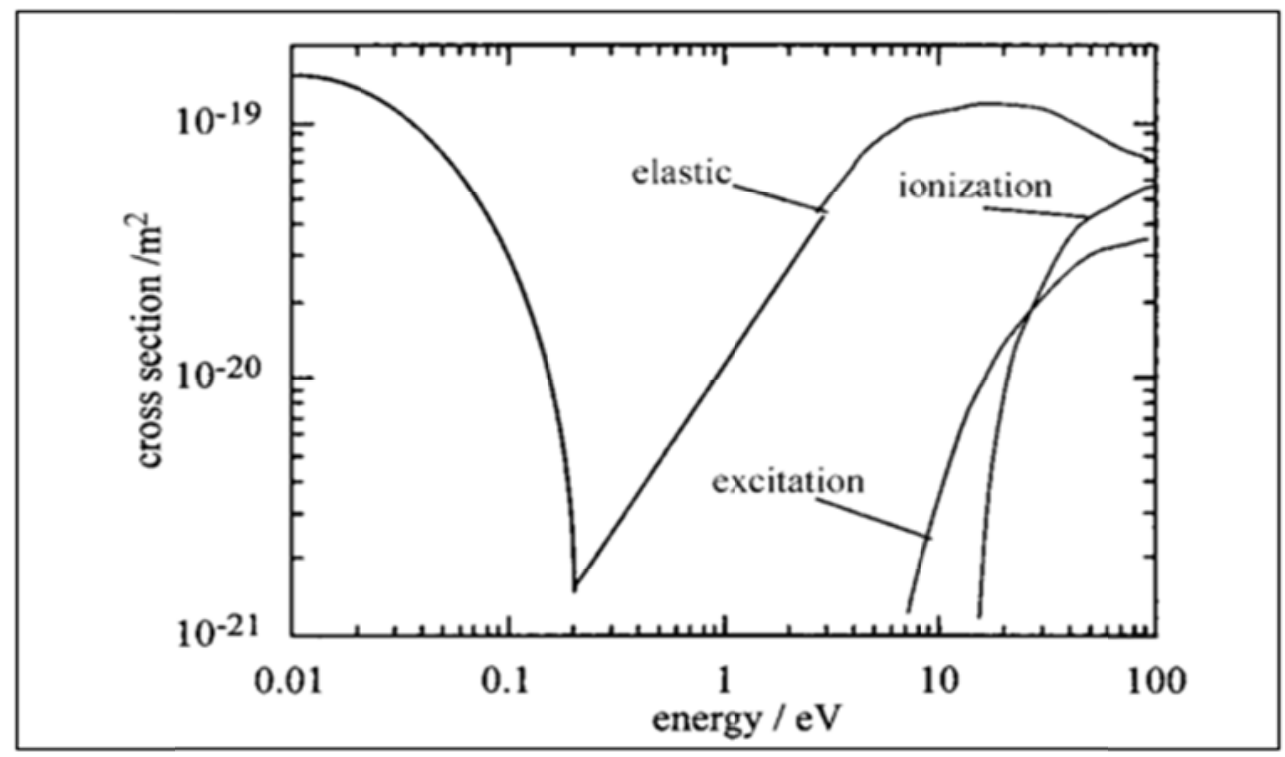

Fig. 2: Cross sections for argon [12].

\section{Simulation preparation for used module}

Two dimensional (axial-symmetric) model of dc discharge in low pressure argon gas were done using COMSOL Multiphysics software based on a fluid model with drift-diffusion approximation for the particle flux.

Fig. 3 illustrates the 2D geometries axisymmetric for the electrodes configuration and the meshes distributions. Disc copper cathode system with $3.75 \mathrm{~cm}$ radius and ring cathode with outer radius $3.75 \mathrm{~cm}$ and inner radius $2.5 \mathrm{~cm}$. The radius of anode is $3.75 \mathrm{~cm}$ with $4 \mathrm{~cm}$ inter electrodes separation.

Fine mesh elements is required close to the electrodes, because a large gradient of the electric field. At the same time, a large mesih elements can be used in areas where the variation of the voltage is relatively small, and also in areas which are not of large interest for the particular calculation to minimized solution time. Number of triangular mesh elements used in this work are 3557 and 3619 triangles in disc and ring cathode systems respectively. 


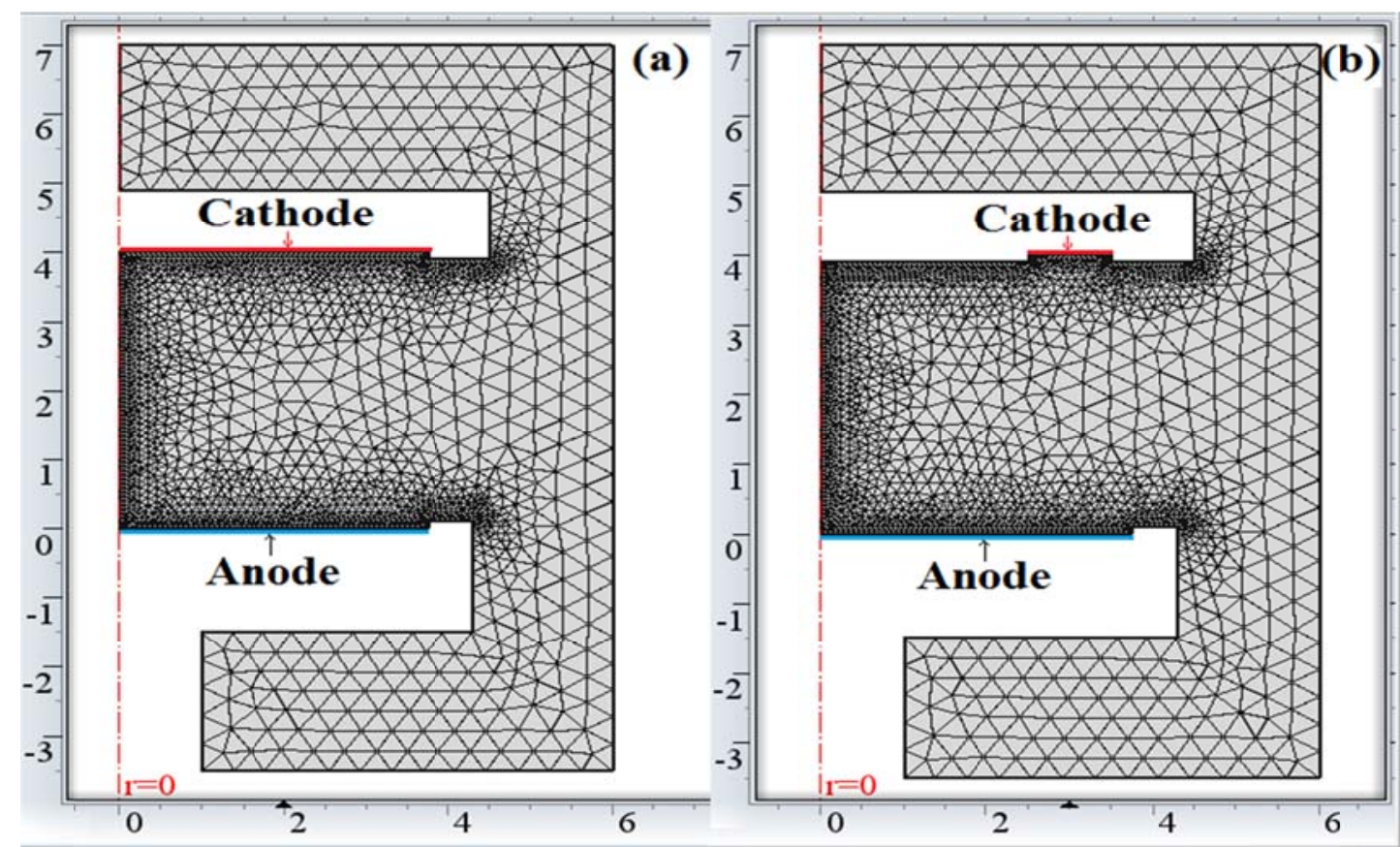

Fig. 3 Two dimensional geometry used in simulation for (a) disc and (b) ring cathodes.

Seven kinds of species transportation in argon plasma were used in simulation as shown in Table 1.

Table 1: Kinds of species within plasma used in simulation.

\begin{tabular}{|c|c|c|c|c|}
\hline No. & species & Symbol & Charge & mass \\
\hline 1 & Electron & $\mathrm{e}$ & $-1.6 \times 10^{-19} \mathrm{C}$ & $\mathrm{m}_{\mathrm{e}}$ \\
\hline 2 & Neutral argon atom & $\mathrm{Ar}$ & 0 & $39.94 \times \mathrm{m}_{\mathrm{p}}$ \\
\hline 3 & Argon ion & $\mathrm{Ar}+$ & $1.6 \times 10^{-19} \mathrm{C}$ & $39.94 \times \mathrm{m}_{\mathrm{p}}$ \\
\hline 4 & Excited argon atom & $\mathrm{Ar}$ & 0 & $39.94 \times \mathrm{m}_{\mathrm{p}}$ \\
\hline 5 & Neutral copper atom & $\mathrm{Cu}$ & 0 & $63.55 \times \mathrm{m}_{\mathrm{p}}$ \\
\hline 6 & Copper ion & $\mathrm{Cu}+$ & $1.6 \times 10^{-19} \mathrm{C}$ & $63.55 \times \mathrm{m}_{\mathrm{p}}$ \\
\hline 7 & Excited copper atom & $\mathrm{Cu}^{*}$ & 0 & $63.55 \times \mathrm{m}_{\mathrm{p}}$ \\
\hline
\end{tabular}

where $\mathrm{m}_{\mathrm{e}}=9.11 \times 10^{-31} \mathrm{~kg}$ and $\mathrm{m}_{\mathrm{p}}=$ $1.67 \times 10^{-27} \mathrm{~kg}$ denoted to electron and proton masses respectively.

Table 2 and 3 show the reactions used in simulation which is the dominant reaction in both gas phase and surfaces reactions, respectively, and the related energy difference.

Table 2: Electron reactions within plasma used in simulation and its references for cross section data as a function of the electron energy.

\begin{tabular}{|c|c|c|cc|}
\hline No. & Process & Reaction & 0 & Energy (eV) \\
\hline 1 & Elastic collision & $\mathrm{e}+\mathrm{Ar}=>\mathrm{e}+\mathrm{Ar}$ & 11.6 & {$[13]$} \\
\hline 2 & Excitation collision & $\mathrm{e}+\mathrm{Ar}=>\mathrm{e}+\mathrm{Ar}^{*}$ & 15.8 & {$[15]$} \\
\hline 3 & Ionization collision & $\mathrm{e}+\mathrm{Ar}=>2 \mathrm{e}+\mathrm{Ar}^{+}$ & 4.14 & {$[15]$} \\
\hline 4 & Stepwise ionization & $\mathrm{e}+\mathrm{Ar}^{*}=>2 \mathrm{e}+\mathrm{Ar}^{+}$ & -11.5 & {$[14]$} \\
\hline 5 & Quenching to base state & $\mathrm{e}+\mathrm{Ar}^{*}=>\mathrm{e}+\mathrm{Ar}$ & & \\
\hline
\end{tabular}


Table 3: The surfaces reactions used in simulation [16].

\begin{tabular}{|c|c|c|c|}
\hline No. & Reaction & Surface & $\begin{array}{c}\text { Emitted Electron Energy } \\
(\mathrm{eV})\end{array}$ \\
\hline 1 & $\mathrm{Ar}^{+}=>\mathrm{Ar}$ & Cathode & $\mathrm{E}=\mathrm{E}_{\text {ion }(\mathrm{Ar})}-2 \varphi_{\mathrm{cu}}=6.76 \mathrm{eV}$ \\
\hline 2 & $\mathrm{Ar}+=>\mathrm{Ar}$ & Non cathode walls & - \\
\hline 3 & $\mathrm{Ar}{ }^{*}=>\mathrm{Ar}$ & All walls & - \\
\hline 4 & $\mathrm{Ar}^{+}+\mathrm{Cu}(\mathrm{s})=>\mathrm{Ar}+\mathrm{Cu}$ & $\mathrm{Cu}$ Cathode & - \\
\hline 5 & $\mathrm{Cu}+=>\mathrm{Cu}$ & Non cathode walls & - \\
\hline 6 & $\mathrm{Cu}^{*}=>\mathrm{Cu}$ & All walls & \\
\hline
\end{tabular}

where $\mathrm{Cu}(\mathrm{s})$ meant to solid $\mathrm{Cu}$, $\mathrm{E}_{\mathrm{i}(\mathrm{Ar})}$ represent to first ionization energies for $\mathrm{Ar}=15.759 \mathrm{eV}$ [17], $\varphi_{\mathrm{Cu}}$ is the work functions of $\mathrm{Cu}(4.51 \mathrm{eV}$ [18]).

The secondary ionization coefficient $\gamma$ considered as [19] $\gamma \approx$ $(0.016 / \mathrm{eV})\left(\mathrm{E}_{\text {ion(Ar) }}-2 \varphi_{\mathrm{Cu}}\right)$.

\section{Experimental Part}

The main experimental setup of $\mathrm{dc}$ discharge plasma system was shown in Fig.4 which consist of: double stage rotary pump, a glass chamber with diameter of $(20 \mathrm{~cm})$ and height of $(30 \mathrm{~cm})$, transparent plastic base (with rubber ring, gas entrance and electrical feed-through), pirani head and reader, H.V dc-power supply $(3 \mathrm{kV})$, multimeter for discharging current measurements, high volltage voltmeter. The gas source - flow controllers system which used for delivering Ar gas to plasma chamber at desired flow rate and gas pressure. It consists of the argon gas storage cylinders, regulators, tubing and needle valve.

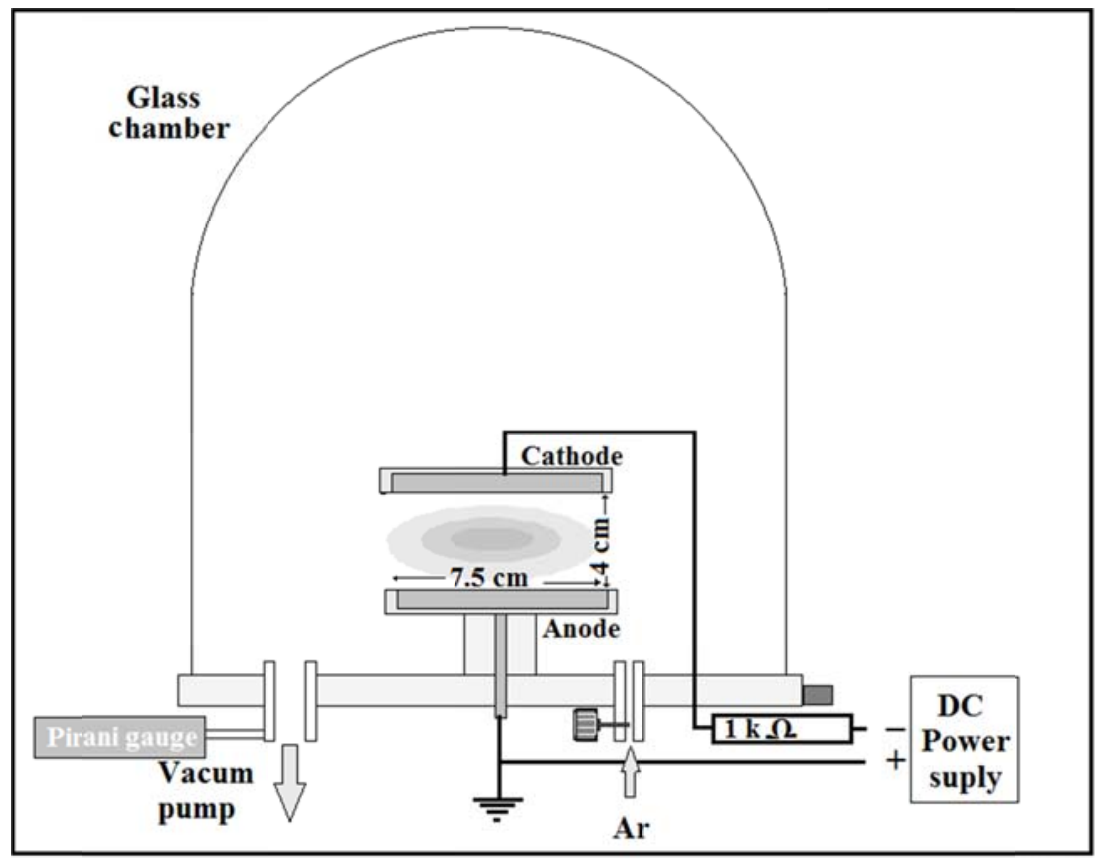

Fig. 4: Schematic for experimental setup.

The cathodes holder were designed to allowed the arrangement of disc or ring copper cathode as shown in Fig. 5. 


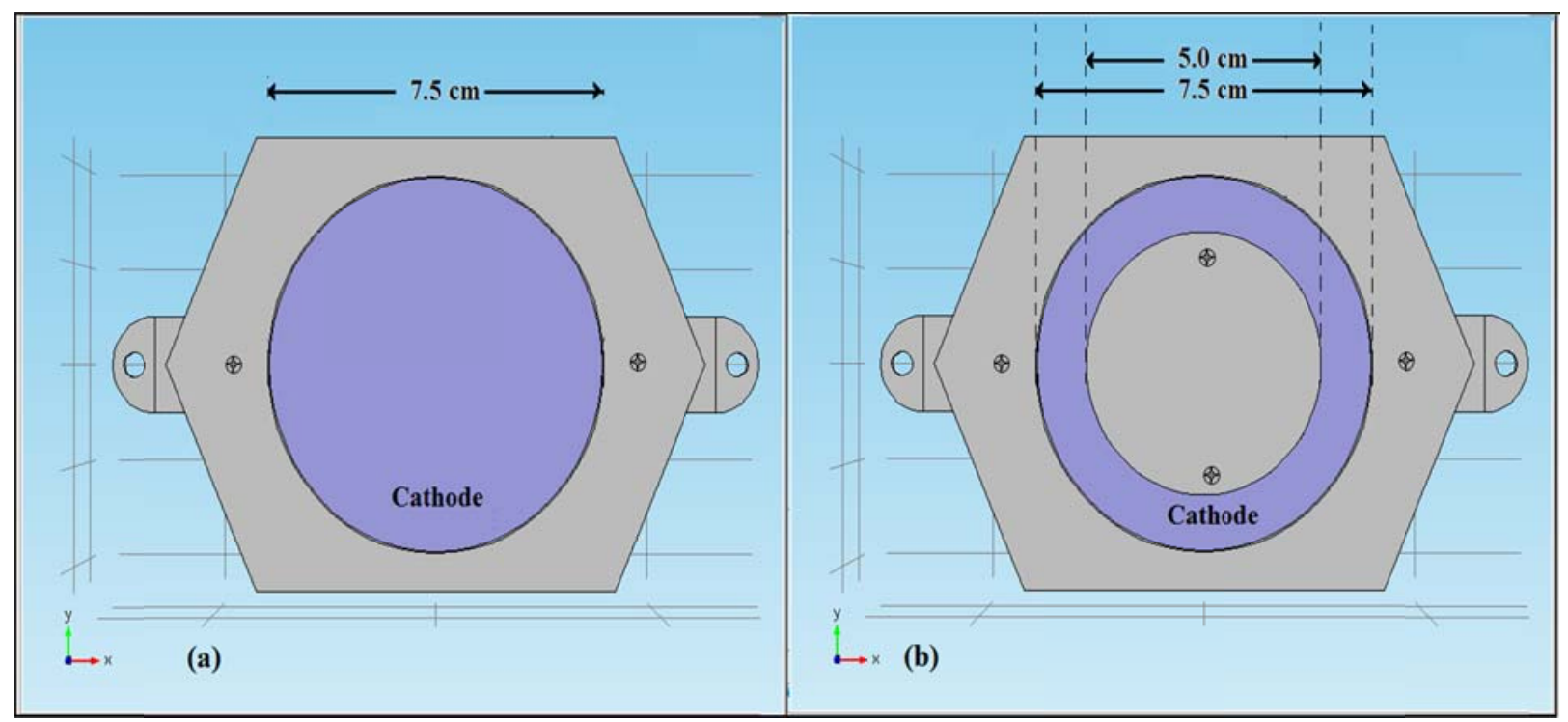

Fig. 5: Cathode holder design (a) disc cathode and (b) ring cathode.

In order to study the uniformity of deposition thickness, from disc and ring cathodes, A glass slide with dimension $2.5 \times 4 \mathrm{~cm}$, previously cleaned, put on anode as its terminal in the center, as shown in Fig. 6, to measure thicknesses at different radial position $(\mathrm{r}=0,1.25,2.5$ and $3.75 \mathrm{~cm})$.

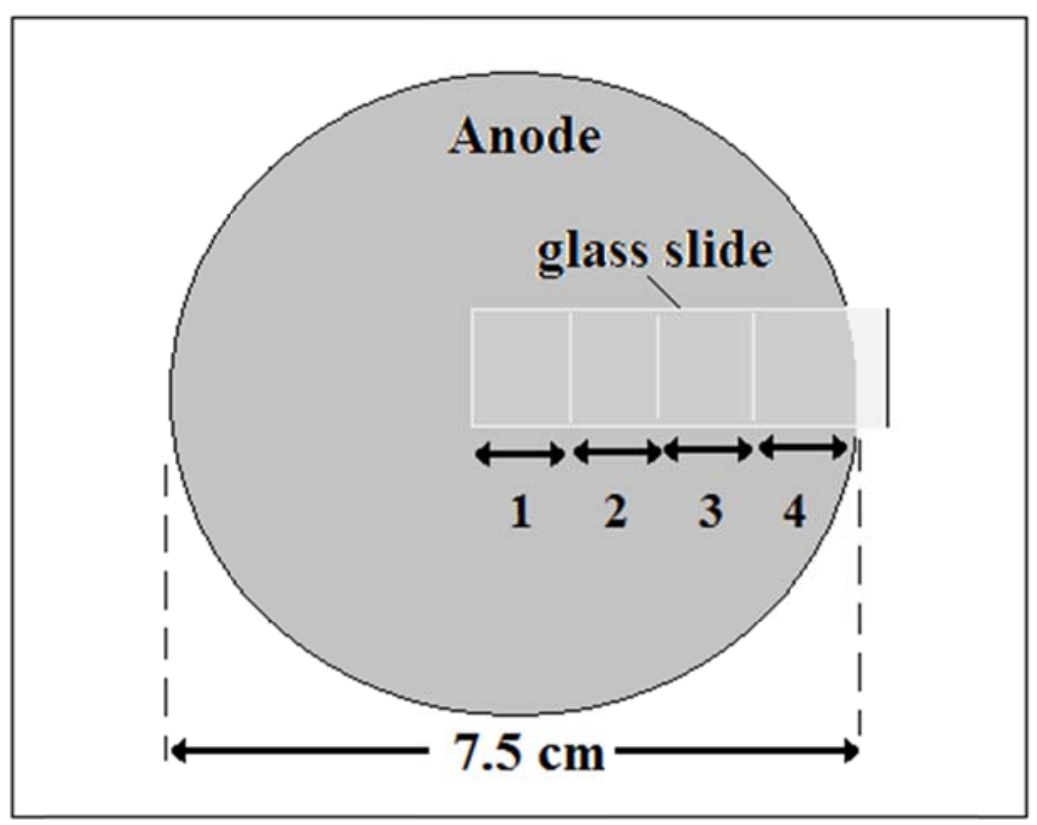

Fig. 6: Schematic of top view for anode and the glass substrate position to study deposition thickness uniformity at different radial position.

A series of films were synthesized at constant pressure 0.2 mbar at -700 and -1000 volt for disc and ring cathodes. Films thicknesses deposited on glass slides were measured by using an optical spectroscopic reflectometer (TFProbe TM from Angstrom Sun
Technology Inc.) by measurement of the reflectivity at (0) angle light falling and investigated on maximum and minimum values of reflectivity, then uses the refractive index of the material to calculate the true thickness from optical thickness. 


\section{Simulation results}

Fig. 7 shows the simulation result of excitation reactions rate at constant pressure (of 0.2 mbar) at -700 volt dc applied voltage with inter electrode distance $(4 \mathrm{~cm})$ for both cathode systems. This figure indicate that the plasma glow distributed over more area on the region between the two electrode when using ring cathode but with less intense due to decreasing cathode area.
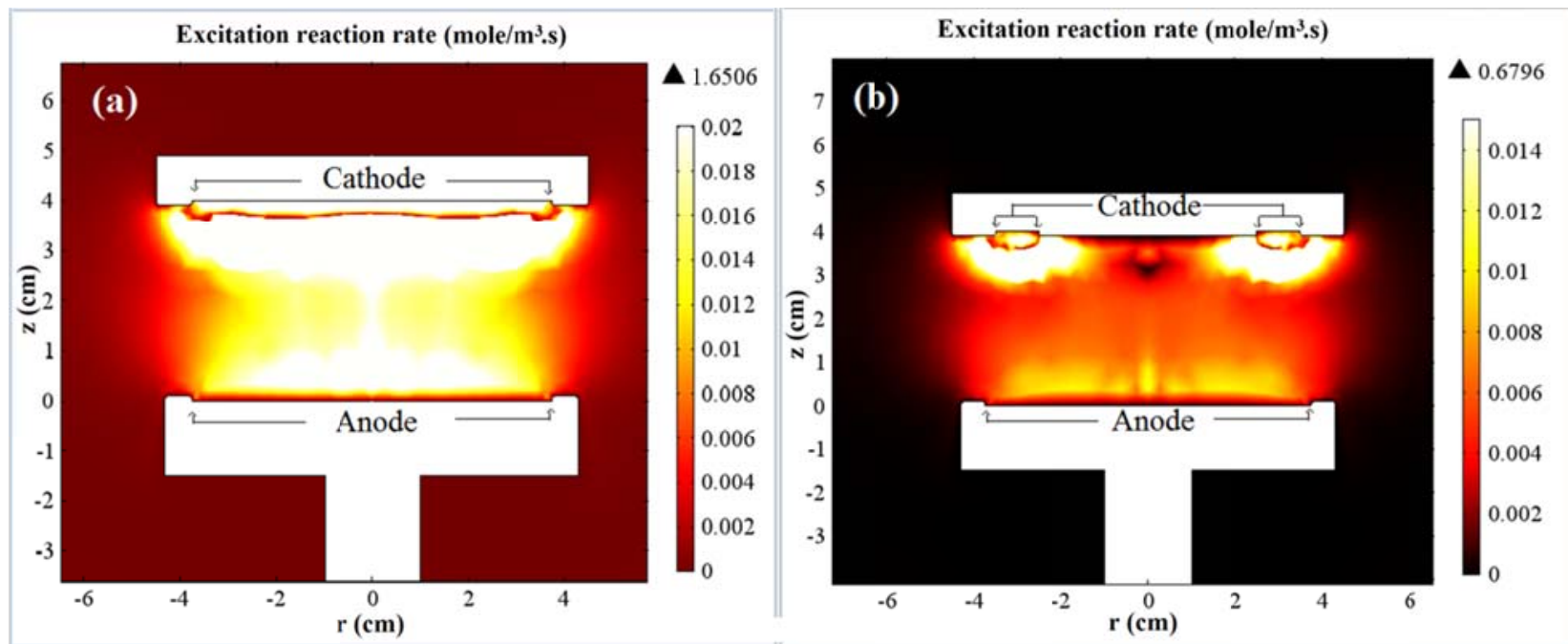

Fig. 7: Comparison between the distribution of excitation reaction rate at $P=0.2$ mbar $d=4$ cm at -700 volt applied voltage for (a) disc cathode (b) Ring cathode.

Fig. 8 shows contour and arrow figure where the arrows length show the $\mathrm{Cu}$ atoms flux amount, deduced from solving continuity and flux equations for neutral $\mathrm{Cu}$ particles at nodes, and their directions show $\mathrm{Cu}$ flux direction, at (0.2 mbar) and $4 \mathrm{~cm}$ electrode distance gap from disc and ring $\mathrm{Cu}$ cathodes. This figure indicate that the $\mathrm{Cu}$ flux using ring cathode less than at disc one, but cover whole the anode with more uniformity.
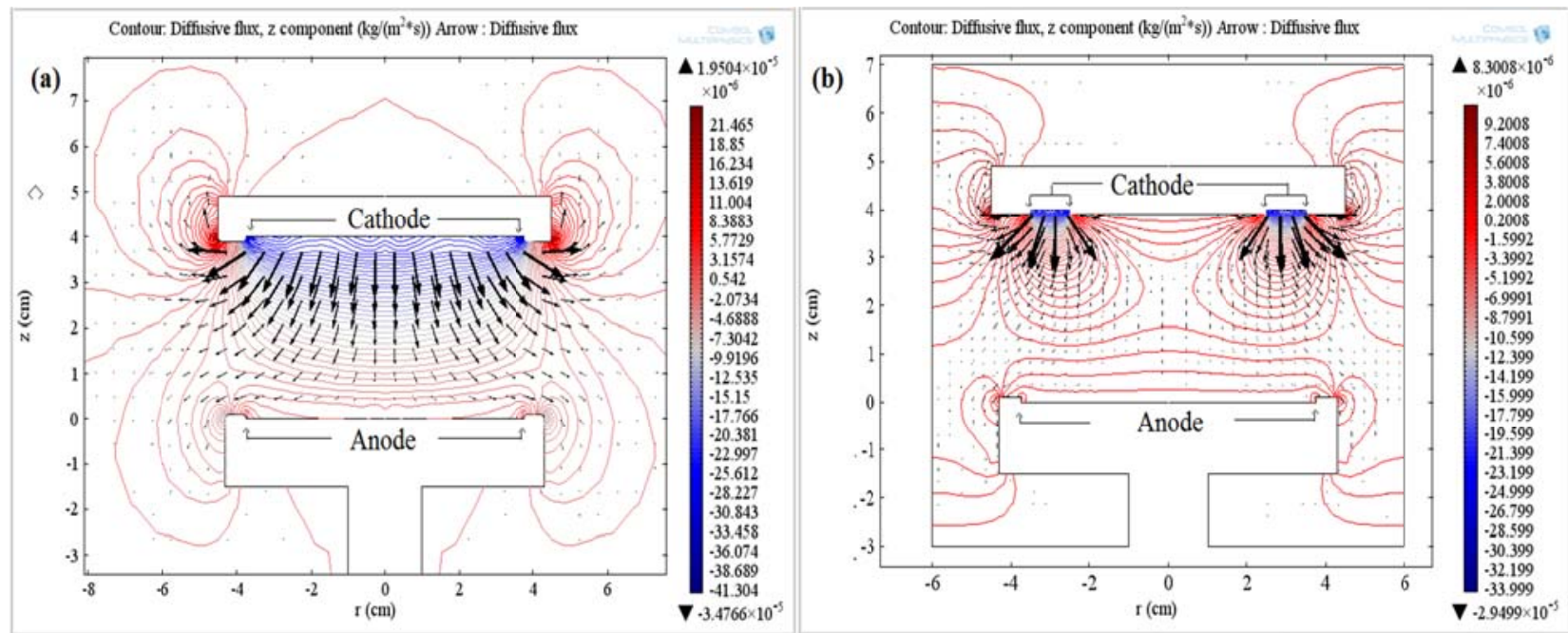

Fig. 8: Distribution of $C u$ flux at $P=0.2$ mbar and $d=4 \mathrm{~cm}$ for (a) disc Cu cathode (b) Ring Cu cathode.

Fig. 9 shows the distribution of rate of deposition on anode, calculated from the $\mathrm{z}$ - component flux for $\mathrm{Cu}$ atom by divided the flux in $\mathrm{Kgm} . \mathrm{m}^{-2} \mathrm{~s}^{-1}$ (from equation 6) by $\mathrm{Cu}$ density, at constant pressure (0.2 mbar) from disc 
copper cathode at different applied dc voltage. This figure shows that the deposition from this target was non uniformed, where the deposition at the center greater than at anode edge. The deposition rate increase with increase applied voltage as a result of increasing colliding ion energy, i.e. increasing sputtering, because sputter yield depend, mainly, on the ions bombarding energy [20].

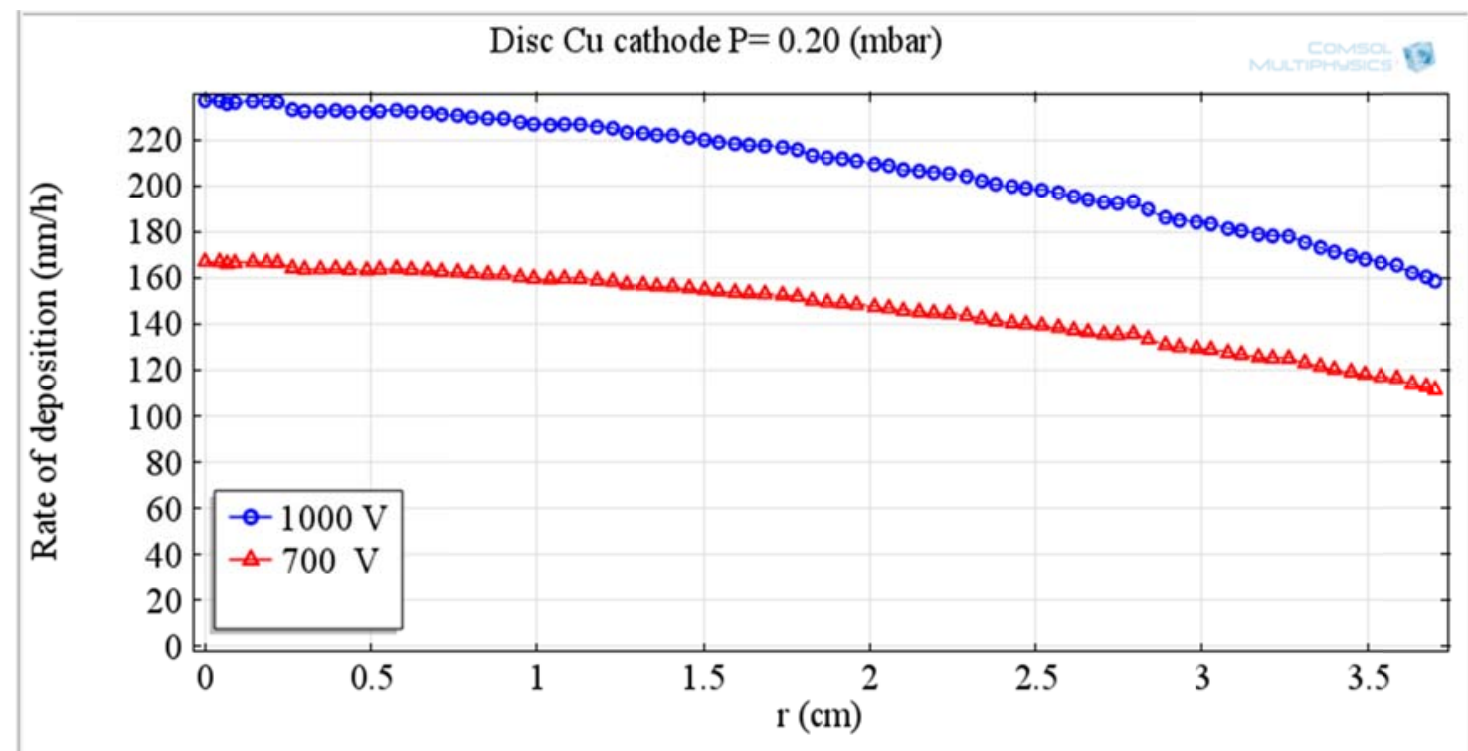

Fig. 9: Rate of deposition distribution over anode with -700 and -1000 applied voltages and constant pressure $(p=0.2$ mbar) from disc copper cathode.

Fig. 10 shows the simulation solution for the distribution of rate of deposition on anode at constant pressure $(0.2$ mbar) from ring cathode made from copper and with different applied voltage. This figure shows that the deposition have more uniformity than the deposition from disc cathodes but with less values than from disc cathode as a result of decreasing cathode area.

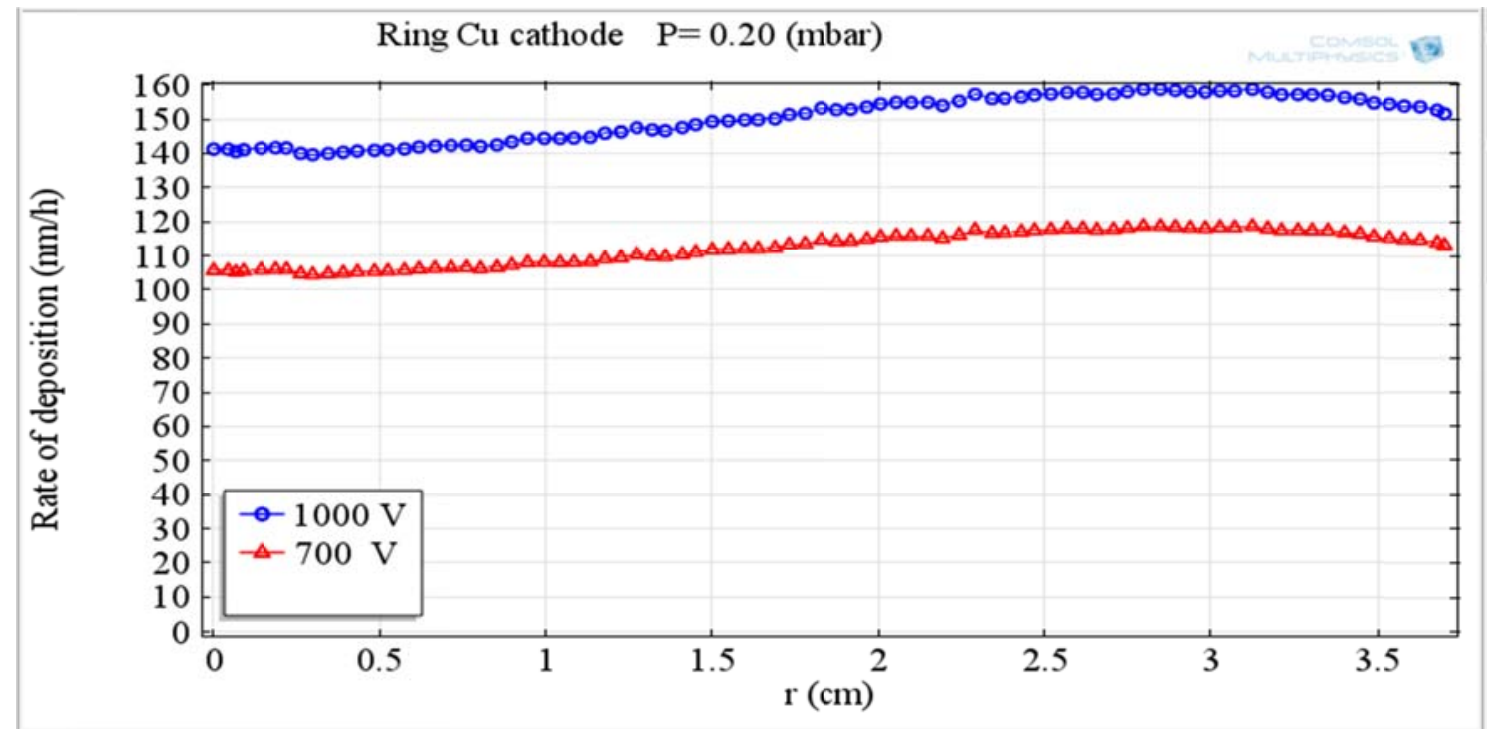

Fig. 10: Rate of deposition distribution over anode with -700 and -1000 volt applied voltage and constant pressure of 0.2 (mbar) from ring copper cathode. 


\section{Comparison with experiment result}

The study has been applied in practice to do a comparison between the two types of electrodes and compare the results with simulation results. Fig. 11 illustrates experimental photograph for dc glow discharge at working pressure of $0.2 \mathrm{mbar}$ and electrode distance gap $4 \mathrm{~cm}$, for both cathode systems configurations. The result indicated that the glow distribution being more uniformly and sprayed out on more region when using ring cathode, and have same behavior with excitation reaction rate distribution deduced from simulation results because the reaction cause the glow is the excitation resection.

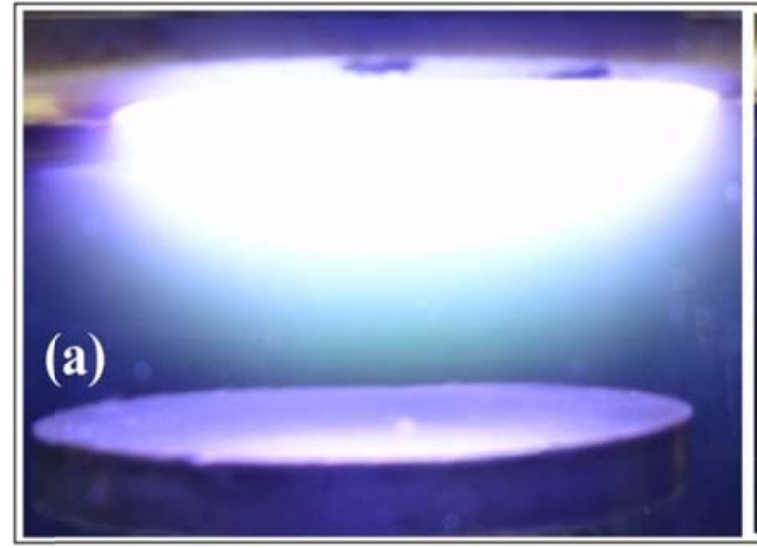

Fig. 11: DC discharge glow image from (a) disc cathode (b) ring cathode.
Fig. 12 shows the experimental result for rate of deposition on anode at constant pressure $(0.2$ mbar) from disc copper cathode using applied voltage 700 and -1000 volt, calculated by measuring film thicknesses at different radial positions. This figure shows that the deposition from this target was non uniformed, have the same performance of simulation results, but with less values, maybe due to supposing, in simulation, that all metal atom flux hit

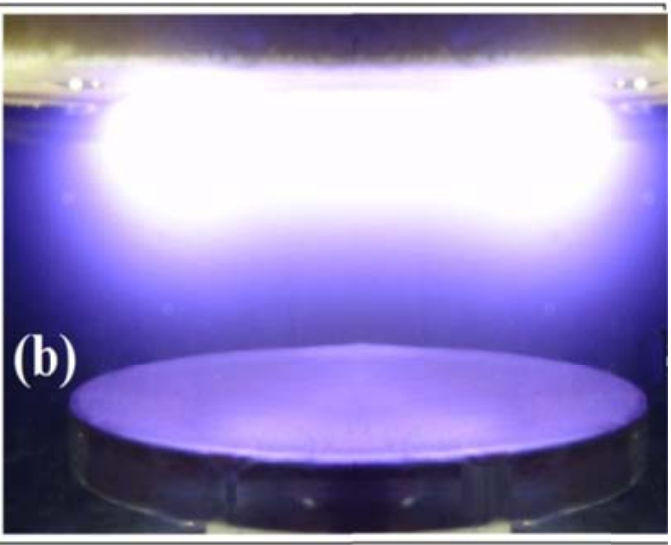

the anode deposited on it (no atoms reflected). The deposition rate increases with increasing of applied voltage as a result of increasing colliding ion energy. The deposition rate at small applied voltage is very small, very difficult to be measured, not as expected in simulation results may be due to sputter yield very small with low ions energy, not as assumed in simulation part.

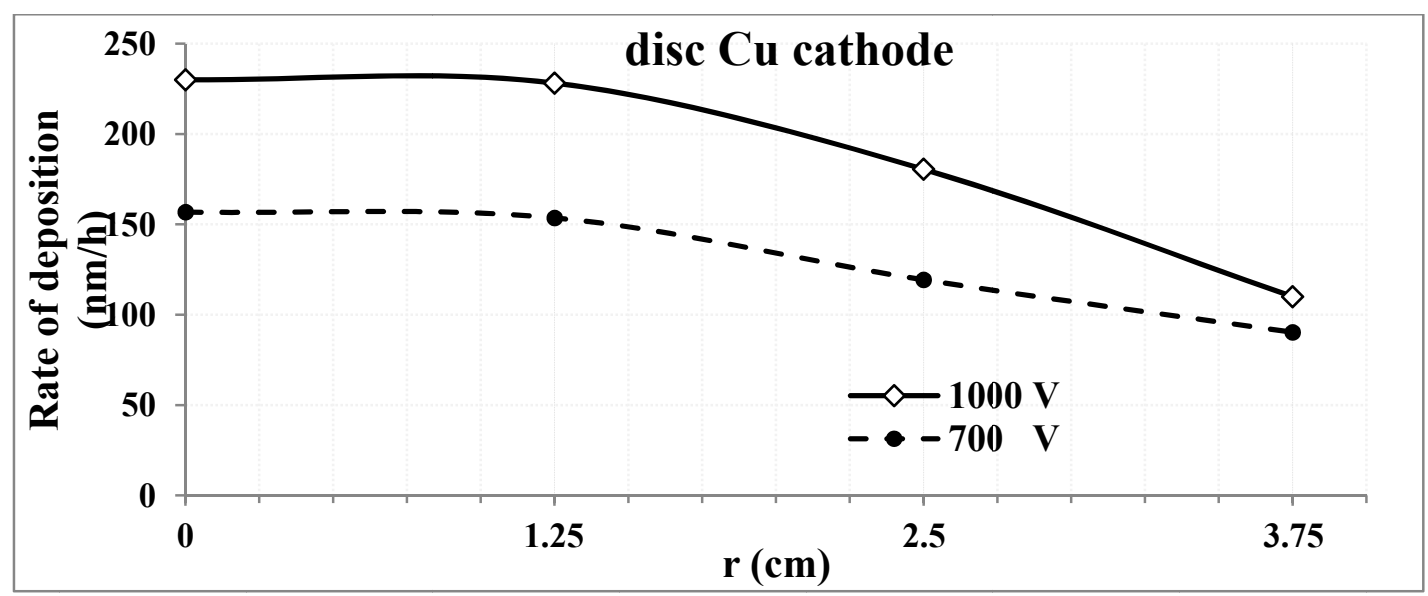

Fig. 12: Experimental results for rate of deposition at different radial position using disc cathode at -700 and -1000 volt applied voltage. 
Fig. 13 shows the experimental result for rate of deposition on anode at constant pressure $(0.2 \mathrm{mbar})$ from ring cathode made from copper and with applied voltage $(-700$ and $-1000 \mathrm{~V})$ calculated by measuring film thicknesses at different radial position.
This figure shows that the deposition have more uniformity than the deposition from disc cathodes but it less than from disc cathode as shown in the comparison between the two systems configurations in Table 4.

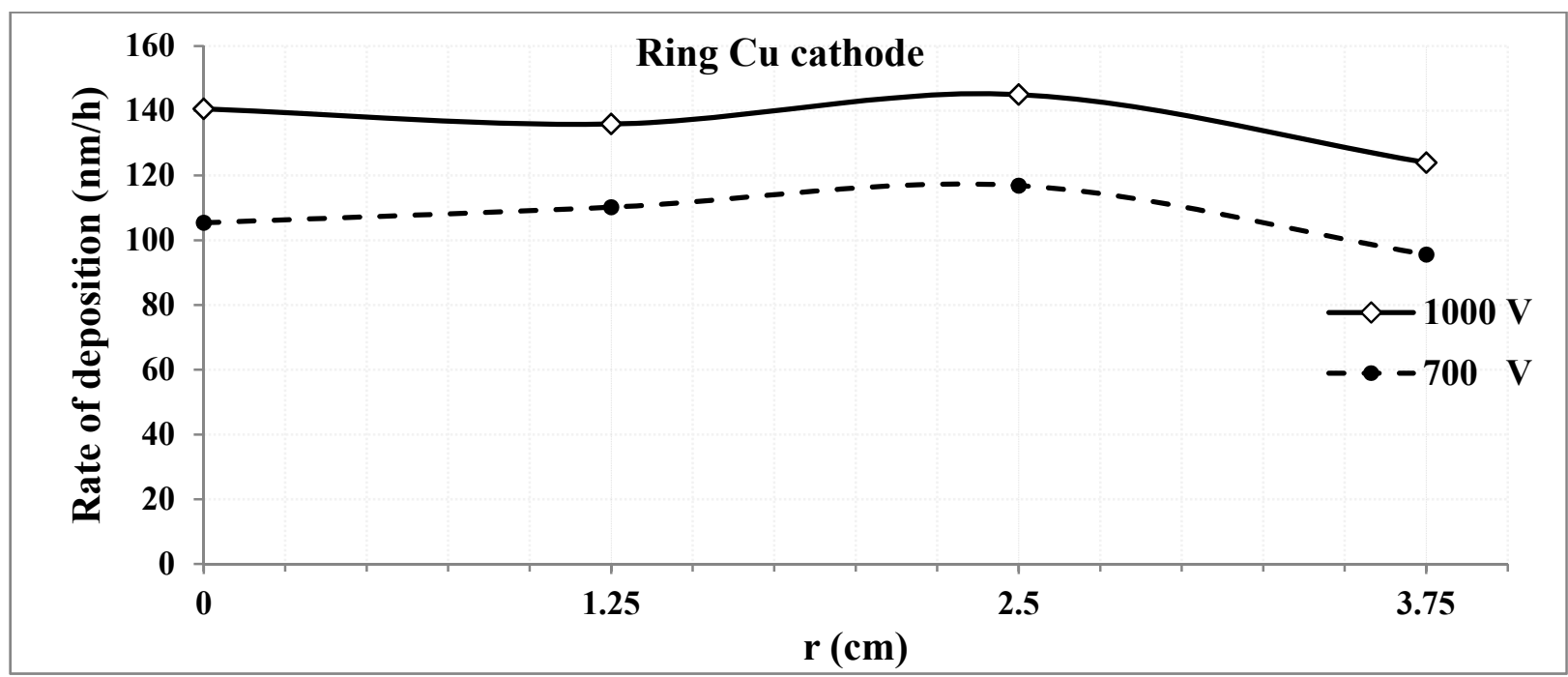

Fig. 13: Experimental results for rate of deposition at different radial position using ring cathode at -700 and -1000 volt applied voltage.

Table 4: Comparison between simulation and experimental results for deposition rate $(\mathrm{nm} / \mathrm{h})$ for disc and ring cathode at -700 and $-1000 \mathrm{~V}$.

\begin{tabular}{|c|c|c|c|c|}
\cline { 2 - 5 } \multicolumn{1}{c|}{} & \multicolumn{2}{c|}{ Simulation results $($ disc $\mathrm{Cu})$} & \multicolumn{2}{c|}{ Experimental results (disc Cu) } \\
\hline $\mathrm{r}(\mathrm{cm})$ & $-700 \mathrm{~V}$ & $-1000 \mathrm{~V}$ & $-700 \mathrm{~V}$ & $-1000 \mathrm{~V}$ \\
\hline 0.00 & 166.9 & 236.7 & 156.80 & 230.00 \\
\hline 1.25 & 157.0 & 223.0 & 153.60 & 228.20 \\
\hline 2.50 & 139.6 & 198.5 & 119.30 & 180.50 \\
\hline 3.75 & 109.4 & 156.6 & 90.30 & 110.00 \\
\hline & \multicolumn{2}{|c|}{ Simulation results (Ring Cu) } & \multicolumn{2}{c|}{ Experimental results $\mathrm{Ring} \mathrm{Cu})$} \\
\hline $\mathrm{r}(\mathrm{cm})$ & $-700 \mathrm{~V}$ & $-1000 \mathrm{~V}$ & $-700 \mathrm{~V}$ & $-1000 \mathrm{~V}$ \\
\hline 0.00 & 105.6 & 141.1 & 105.40 & 140.60 \\
\hline 1.25 & 110.2 & 147.4 & 110.20 & 135.90 \\
\hline 2.50 & 117.5 & 157.1 & 116.90 & 145.10 \\
\hline 3.75 & 111.4 & 150.8 & 95.60 & 124.00 \\
\hline
\end{tabular}

\section{Conclusions}

In our work, we simulate dc sputtering in argon gas for the two cathode electrode configurations using 2D axial symmetric by COMSOL software, where the study showed that the simulation results gives us a good prediction of the uniformity of deposition on the anode. The study showed that the distribution of deposition on the anode be more regularly using ring electrode than the disc cathode. The experimental result for rate of deposition on anode at constant pressure from disc and ring copper cathode using -700 and -1000 volt at different radial position approximately have the same behaviors of simulation results, but with less values, maybe due to supposing in simulation that no reflected metal atoms from anode. The 
deposition rate increase with increase applied voltage as a result of increasing colliding ion energy.

\section{References}

[1] A. Bogaerts, E. Bultinck, I. Kolev, L. Schwaederlé, K. Van Aeken, G. Buyle, D. Depla, J. Phys. D. Appl. Phys., 42 (2009) 194018.

[2] T. Farouk, B. Farouk, D. Staack, A. Gutsol, A. Fridman, Plasma Source Sci Techno, 676, (2006) 676-688.

[3] K. Liu, R. Liao, X. Zhao, J. Electr Eng Technol, 10 (2015) 709-718.

[4] M. Weston, "Fusion Plasma Physics", vol. 1. Wiley-VCH Verlag GmbH \& Co. kGaA, (2015), p. 85.

[5] D. Zhang, "Surface Reaction Mechanism in Plasma Etching Processes," University of Illinois at Urbana-Champaign, (2000), p. 24.

[6] A. Dinklage, T. Klinger, G. Marx, S. L, Plasma Physics, 21, 529 (2005), p. 62.

[7] G. E. Georghiou, A. P. Papadakis, R. Morrow, J. Appl. Phys., 38 (2005), 303.

[8] B. G. David, "Gaseous Ionization and Ion Transport: An Introduction to Gas Discharges," University of Notre Dame, (2012), p.7.

[9] F.F.Chen, Journal of Chemical Information and Modeling, 53 (1989), 160.
[10] B. M. Smirnov, "Physics of ionized gases", vol. 20. New York: John Wiley \& Sons, Inc., (2004), p 37. [11] Q. Wang, D. Economou, V. Donnelly, J. Appl. Phys., 100 (2006) 110

[12] F. Hall and B. Hill, Plasma Sources Sci. Technol., 9 (2000) 517527.

[13] M. Hayashi, Nagoya Institute of Technology, Report No IPPJ-AM-19 (1991).

[14] K. Tachibana, Phys. Rev. A, 34 (1986) 1007.

[15] E. Rokni and M. Elson, J. Phys. D, 29. 3, (1996).

[16] T. Farouk, B. Farouk, D. Staack, A. Gutsol, A. Fridman, Plasma Sources Sci. Technol, 15 (2006) 676-688.

[17] J. E. Sansonetti and W. C. Martin, Am. Inst. Phys., 34, 4 (2005) 1582.

[18] D. R. Lide, "CRC Handbook of Chemistry and Physics," Handb. Chem. Phys., vol. 53, no. 84th Edition, (2003).

[19] Y. P. Raizer, Gas Discharge Physics. Berlin Heidelberg: SpringerVerlag, (1991).

[20] K. Zoerb, "Differential Sputtering Yields of Refractory Metals by Ion Bombardment at Normal and Oblique Incidences," Colorado State University, (2007), p.22. 